\title{
A Comparison of Serum Bilirubin, CTP and Meld Score in Patients with HBV-ACLF
}

\author{
Dr. Sharker Mohammad Shahadat Hossain ${ }^{*}$, Professor Dr. Mamun Al Mahtab (Shwapnil) ${ }^{2}$, Professor Salimur Rahman ${ }^{3}$
}

\author{
${ }^{1}$ Assistant Professor, Department of Hepatology, Kurmitola General Hospital, Dhaka, Bangladesh \\ ${ }^{2}$ Chairman, Department of Hepatology, Bangabandhu Sheikh Mujib Medical University (BSMMU), Dhaka, Bangladesh \\ ${ }^{3}$ Former UGC Professor \& former Professor, Department of Hepatology, Bangabandhu Sheikh Mujib Medical University (BSMMU), Dhaka, \\ Bangladesh
}

DOI: $10.36347 /$ sjams.2020.v08i11.019

| Received: 24.10.2020 | Accepted: 09.11.2020 | Published: 14.11.2020

*Corresponding author: Dr. Sharker Mohammad Shahadat Hossain

Background: Billirubin is a yellowish substance in blood. It forms after red blood cells break down, and it travels through your blood. It forms after red blood cells break down, and it travels through your liver, gallbladder and digestive tract before being excreted. Typically, billirubin levels fall somewhere between 0.3 and 1.2 milligrams per deciliter ( $\mathrm{mg} / \mathrm{dl})$. A billirubin test measures the amount of billirubin in your blood. It's used to help find the cause of health condition like jaundice, anemia and liver disease. Bilirubin is an orange-yellow pigment that occurs normally when part of your red blood cells break down. The liver, however, is able to replace damaged tissue with new cells. If up to 50 to 60 percent of the liver cells may be killed within three to four days in an extreme case like Tylenol overdose, the liver will repair completely after 30 days if no complications arise. Child-Turcotte-Pugh (CTP), model for end stage liver disease (MELD) and MELD sodium (MELD-Na) scores are used for predicting disease severity and mortality among patients with end-stage liver disease. If MELD score is under 10: It will be recalculated once a year: 11-18: It will be recalculated every 3 months. 19-24: It will be recalculated once a month. 25 or higher: It will be recalculated every week. Aims: The goal to see the comparison of serum bilirubin, CTP and Meld score in patients with HBV-ACLF. Methodology: In this study a total of 32 acute on chronic Hepatitis B liver failure patients (age > 18 years with both sexes but male predominant) were included in Hepatology department of Bangabandhu Sheikh Mujib Medical University, Dhaka during January 2013 to December 2015. The patients were randomized into two groups: Tenofovir group $(\mathrm{N}=16)$ and Entecavir group $(\mathrm{N}=16)$ and followed at least for 03 months. Result: The total study population was 32 patients $16(50.00 \%)$ males and $16(50.00 \%)$ females. Table-1 demonstrted the characteristics of patients with serum bilirubin, CTP and Meld score show the distribution of the studied population according to sex. Different follow up of serum Bilirubin mean $n=32$ Patients Figure-2 shows (19.8), (22) patients mean tenofovir and Enteccavir group respectively had pretreament, (17.8), (20.7) patients mean tenofovir and Enteccavir group respectively had 7 days (First Follow-up), (15.5), (17.9) patients mean tenofovir and Enteccavir group respectively had 14 days (Second Follow-up) and (1.9), (5.1) patients mean tenofovir and Enteccavir group respectively had 90 days (Third Follow-up). Different follow up of CTP (Child-Turcotte Pugh score) mean $n=32$ patients Figure-2 shows (12.1), (12) patients mean tenofovir and Enteccavir group respectively had pretreament, (10.4), (11.9) patients mean tenofovir and Enteccavir group respectively had 7 days (First Follow-up), (9.6), (11.3) patients mean tenofovir and Enteccavir group respectively had 14 days (Second Follow-up) and (5.8), (9.3) patients mean tenofovir and Enteccavir group respectively had 90 days (Third Follow-up). Different follow up of MELD Score mean n=32 Patients Figure-3 shows (25), (26.5) patients mean tenofovir and Enteccavir group respectively had pretreament, (23.3), (25.9) patients mean tenofovir and Enteccavir group respectively had 7 days (First Follow-up), (22.5), (24.7) patients mean tenofovir and Enteccavir group respectively had 14 days (Second Follow-up) and (9.3), (17) patients mean tenofovir and Enteccavir group respectively had 90 days (Third Follow-up). Conclusion: In HBV-ACLF patients, the use of nucleoside and nucleotide analogs has clear survival benefit, which is significantly higher with Tenofovir. Early interventions by antiviral therapy improve survival rates of HBV-ACLF patients and early intervention by tenofovir improves more survival.

Keywords: Serum bilirubin, CTP (Child-Turcotte-Pugh), Meld score.

Copyright $\odot 2020$ The Author(s): This is an open-access article distributed under the terms of the Creative Commons Attribution 4.0 International License (CC BY-NC 4.0) which permits unrestricted use, distribution, and reproduction in any medium for non-commercial use provided the original author and source are credited.

\section{INTRODUCTION}

Billirubin is a yellowish substance in blood. It forms after red blood cells break down, and it travels through your blood. It forms after red blood cells break down, and it travels through your liver, gallbladder and digestive tract before being excreted. Typically, billirubin levels fall somewhere between 0.3 and 1.2 milligrams per deciliter $(\mathrm{mg} / \mathrm{dl})$. A billirubin test measures the amount of billirubin in your blood. It's 
used to help find the cause of health condition like jaundice, anemia and liver disease. Bilirubin is an orange-yellow pigment that occurs normally when part of your red blood cells break down. The liver, however, is able to replace damaged tissue with new cells. If up to 50 to 60 percent of the liver cells may be killed within three to four days in an extreme case like Tylenol overdose, the liver will repair completely after 30 days if no complications arise. Child-Turcotte-Pugh (CTP), model for end stage liver disease (MELD) and MELD sodium (MELD-Na) scores are used for predicting disease severity and mortality among patients with end-stage liver disease. If MELD score is under 10: It will be recalculated once a year: 11-18: It will be recalculated every 3 months. 19-24: It will be recalculated once a month. 25 or higher: It will be recalculated every week. The term ACLF was first used in 1995 to describe a condition in which two insults to the liver are operating simultaneously, one of them are being ongoing and chronic while the other being acute [1]. Acute on chronic liver failure (ACLF) is an increasingly recognized distinct disease entity encompassing an acute deterioration of liver function in patients with chronic liver disease [2]. Although there are no widely accepted diagnostic criteria for ACLF, two representative consensus definitions are commonly used. Asia-Pacific Association for the Study of Liver Disease has defined ACLF as an acute hepatic insult manifesting as jaundice and coagulopathy, complicated within 4 weeks by clinical ascites and/or encephalopathy in a patient with previously diagnosed or undiagnosed chronic liver disease/cirrhosis, and is associated with a high 28-day mortality [3]. Acute on chronic liver failure (ACLF) is currently recognized as a specific entity characterized by acute deterioration of liver function in the context of compensated or even decompensated, but hitherto stable, cirrhosis [4]. Chronic hepatitis B virus (HBV) infection is a serious health problem because of its worldwide distribution and its potential adverse sequelae, including cirrhosis and hepatocellular carcinoma (HCC) [5]. It was estimated that more than 200,000 and 300,000 chronic HBV carriers worldwide die of liver cirrhosis and HCC, respectively, each year [6]. On the other hand short term prognosis of patients with spontaneous severe acute exacerbation of CHB leading to ACLF-like presentation is extremely poor, with a high mortality ranging from $30 \%$ to $70 \%$ [7]. The acute episodes vary depending on the geographic region and the population under study. They include both infectious and noninfectious causes. It was also appreciated that the major etiologic agents responsible for precipitating ACLF are quite distinct in the East and the West. Alcohol and drugs constitute the majority of acute insults in the West, where as infectious etiologies predominate in the East. The difference in the etiologies of ACLF between the East and the West reflects the differences in the etiology of the underlying chronic liver disease in the different geographic regions as well. Among the infectious etiologies, reactivation of hepatitis $B$ virus (HBV) infection is one of the major causes of ACLF in the Asian region [8]. Reactivation may be either spontaneous or due to intensive chemotherapy or immunosuppressive therapy [9], immune restoration after highly active antiretroviral therapy for HIV [10], treatment related [11], or reactivation of the occult HBV infection by rituximab (anti-CD20)-based chemotherapy [12]. Similarly, reactivation of hepatitis $\mathrm{C}$ virus infection has also been reported, especially after immunosuppressive therapy [13]. The other very important infectious etiology of the acute event is super infection with hepatitis $\mathrm{E}$ virus, predominantly in patients in the Indian subcontinent [14]. Mahtab et al., [15], has reported that $\mathrm{HEV}$ is also the commonest acute insult for ACLF in Bangladesh. Various bacterial, parasitic, and fungal infections may affect the liver. Spirochetal, protozoal, helminthic, or fungal organisms may directly infect the liver, whereas bacterial or parasitic infection may spread to the liver from other sites [16]. These infections may lead to liver failure in patients with underlying chronic liver disease. Among the noninfectious etiologies, alcoholic hepatitis is the major cause of acute deterioration in stable known or unknown chronic liver diseases, more often in the western countries [17]. Hepatotoxic drugs and herbal indigenous medicines are important causes for liver failure in the Asia-Pacific region [18]. Acute variceal bleeding has been included as one of the events to define hepatic decompensation in the natural history of cirrhosis [19]. Recent publications from the West have shown that major surgical procedures could pose an acute insult to liver [20].

\section{Methodology}

The study was carried out from From January 2013 to December 2015 Randomized clinical trial at the Inpatient Department of the Department of Hepatology, BSMMU, while patients were admitted through the Outpatient Department of the same Department. Acute on chronic hepatitis B liver failure patients (age >18 years of both sexes) were enrolled as study population. Inclusion criteria: Age: > 18 years, Sex: both sexes, Bilirubin $\geq 5 \mathrm{mg} / \mathrm{dl}$, Coagulopathy (international normalized ratio $\geq 1.5$ ), Complicated by ascites and/or encephalopathy within 4 weeks. Patients with chronic liver disease due to $\mathrm{HBV}$ infection.

Acute insult by reactivation of $\mathrm{HBV}$ or $\mathrm{HBV}$ flare. Exclusion criteria: Age <18 years, Acute insult caused by HEV, HAV, drugs, alcohol etc. Decompensated cirrhosis of liver. Acute on chronic hepatitis B liver failure patient with undetected HBV DNA . Patients with chronic liver disease due to HCV infection, NASH etc. Coexistent hepatocellular carcinoma (HCC), Serum creatinine >1.5 mg/dl. Pregnancy Patients on antiviral drugs, Patients on immunomodulator therapy, Patients on cytotoxic/immunosuppressive therapy, Co-morbidity like heart failure, any malignancy, uncontrolled diabetes etc. Patients unwilling to take part in the study. 
Sampling technique: Purposive (judgment) sampling, Sample size: 32. Patient with clinical suspicion of ACLF were admitted in Department of Hepatology from Outpatient Department. The diagnosis of ACLF was confirmed after proper evaluation and investigations. The study was conducted fulfilling all criteria of good clinical practice according to the Declaration of Helsinki. Written informed consent in Bengali for inclusion into the trial was obtained from all study subjects. Shortly after admission, the patients were enrolled and randomized into two groups with one group receiving tenofovir and other group receiving entecavir. The potential benefits and risks of the use of tenofovir and entecevir and the non-availability of liver transplantation facilities were explained to them. Every alternate patient received tenofovir and entecavir respectively. Tablet tenofovir $(300 \mathrm{mg}$ ) was given orally daily to half of the patients while the other half received tablet entecavir $(0.5 \mathrm{mg})$ orally daily according to APASL ACLF Management Guideline of 2014. Both drugs were administered in empty stomach (at least 2 hours before or 2 hours after meals) along with standard medical therapy and the patients were followed up for 03 months. Permanent address, present address, mobile and land phone number of all patients were recorded and close liaison was maintained with all patients. Patients and/or their relatives were contacted over telephone and by post reminding of them of their follow up visits, in case they were not admitted in the Department of Hepatology, BSMMU at the time of a particular follow up. All adverse events were recorded describing their nature (local or systemic), intensity and the necessary treatment to relieve them according to WHO guidelines (WHO technical report series No. 850, 1995), the intensity degrees of which are as follows: No adverse reaction, Mild; it does not require treatment, Moderate; it requires treatment and disappears with treatment, Severe; it puts the patient's life in danger or produces death. It requires prolonged hospitalization, produces significant or persistent disability or congenital malformations. Dose modification of tenofovir and entecavir was done according to $\mathrm{CrCL}$ level in appropriate cases. In case of tenofovir group, If CrCL 30 to $49 \mathrm{ml} / \mathrm{min}$ : $300 \mathrm{mg}$ orally every 48 hours, If CrCL 10 tO $29 \mathrm{ml} / \mathrm{min}: 300 \mathrm{mg}$ orally every 72 to 96 hours. In case of entecavir group with renal Impairment; if $\mathrm{CrCL}>50$ usual dose of entecavir was $0.5 \mathrm{mg}$ once daily, if CrCL 30 to $<50$, dose was $0.25 \mathrm{mg}$ once daily or $0.5 \mathrm{mg}$ every 48 hours, if CrCL 10 to $<30$, dose was $0.15 \mathrm{mg}$ once daily,or $0.5 \mathrm{mg}$ every 72 hours. Close liaison was maintained with colleagues at Government hospitals (upozilla health complexes and sadar hospitals) closest to the residences of the study subjects as well as with colleagues of private hospitals, where they received treatment, had they fallen ill after discharge from the Department of Hepatology, BSMMU. Cause, time and date of death was recorded in case of every study subject who expired from the hospital records of Department of Hepatology, BSMMU or respective Government or private hospitals in case of deaths of every study subject. Data were collected using a preformed data collection sheet (questionnaire). Base line information was collected from the patient and/or their relatives. All information regarding clinical features was recorded in a data collection sheet. Fasting plasma glucose, alanine aminotransferase (ALT), aspartate aminotransferase (AST), total bilirubin, prothombin time (INR), serum albumin, serum creatinine, serum electrolyte, CBC and alpha fetoprotein (AFP) were done at the Department of Biochemistry, BSMMU, while abdominal ultrasound and upper gastrointestinal (GI) endoscopy were done at the Department of Radiology and Imaging and Department of Hepatology, BSMMU respectively. Severity of the liver disease was assessed by ChildTurcotte Pugh score (CTP) and model for endstage liver disease (MELD) score. Virological tests were done at Department of Virology, BSMMU. For the diagnosis of HBV serology included tests for hepatitis B surface antigen (HBsAg), hepatitis B e antigen (HBeAg), immunoglobulin $\mathrm{M}$ (IgM) anti-HBc, total anti-HBc and anti-HBe done by commercially available enzymelinked immunoassays. HBV DNA estimation was done with the real-time polymerase chain reaction (PCR) method and anti HCV was done by commercially available enzyme-linked immunoassays. Anti HEV IgM and anti HAV IgM were also done by commercially available enzyme-linked immunoassays for diagnosis of acute insult. Every patient received standard medical treatment including intravenous antibiotics, albumin infusion, supervised diet, lactulose, bowel wash and intensive care monitoring. Enteral or parenteral nutrition was provided to those patients where caloric requirement was not fulfilled by mouth. Clinical assessment (appetite, sleep pattern, level of consciousness, bowel habit, color of stool and urine, urine output, jaundice, flapping tremor, ascitis etc.) and investigations $\mathrm{CBC}, \mathrm{ALT}, \mathrm{AST}$, total bilirubin, prothombin time (INR), serum albumin, serum creatinine, serum electrolyte, and serum lactate were done weekly for first two weeks, at the time of deterioration and at day 90. HBV DNA level and ultrasound of abdomen were repeated at day 90.Patients were discharged on the basis of clinical and biochemical improvement. Increase appetite, feeling of wellbeing, reduction of ascites and serum bilirubin below $5 \mathrm{mg} / \mathrm{dl}$ were the basic criteria for hospital discharge in this study. Besides patients were discharged on risk bond, if they were unwilling to continue treatment being admitted in the Department of Hepatology, BSMMU despite not meeting the basic discharge criteria. The primary endpoints were reduction of serum bilirubin, improvement in CTP and MELD scores and reduction in HBV DNA levels and secondary endpoint of the study was survival at 3 months. The mean values were calculated for continuous variables. The quantitative observations were indicated by frequencies and percentages. ChiSquare test was used to analyze the categorical variables, shown with cross tabulation. Student, paired 
t-test, Mann-Whitney U-test and Wilcoxon test were used for continuous variables. $\mathrm{P}$ values $<0.05$ was considered as statistically significant. Prior to the commencement of this study, the research protocol was approved by the Institutional Review Board (IRB) of BSMMU. Objectives of the study along with its procedure, methods, risks and benefits of this study were explained to the patients in easily understandable local language and then informed, written consent in Bengali was taken from each patient. Patients were assured that all information and records will be kept confidential and that the procedure would be beneficial for both the physicians and the patients in making rational approach in case management. Data were collected with a structured form filled by the investigator after interviewing with the sample unit and were presented as tables. Statistical analysis was carried out by the software SPSS version 23.

\section{RESULT}

Table-1: Distribution of Sex group $(n=32)$

\begin{tabular}{|l|l|l|}
\hline Sex & $\mathbf{n = 3 2}$ & $\mathbf{\%}$ \\
\hline Male & 16 & 50.0 \\
\hline Female & 16 & 50.0 \\
\hline
\end{tabular}

The total study population was 32 patients 16 $(50.00 \%)$ males and $16(50.00 \%)$ females. Table-1 demonstrated the characteristics of patients with serum bilirubin, CTP and Meld score show the distribution of the studied population according to sex.

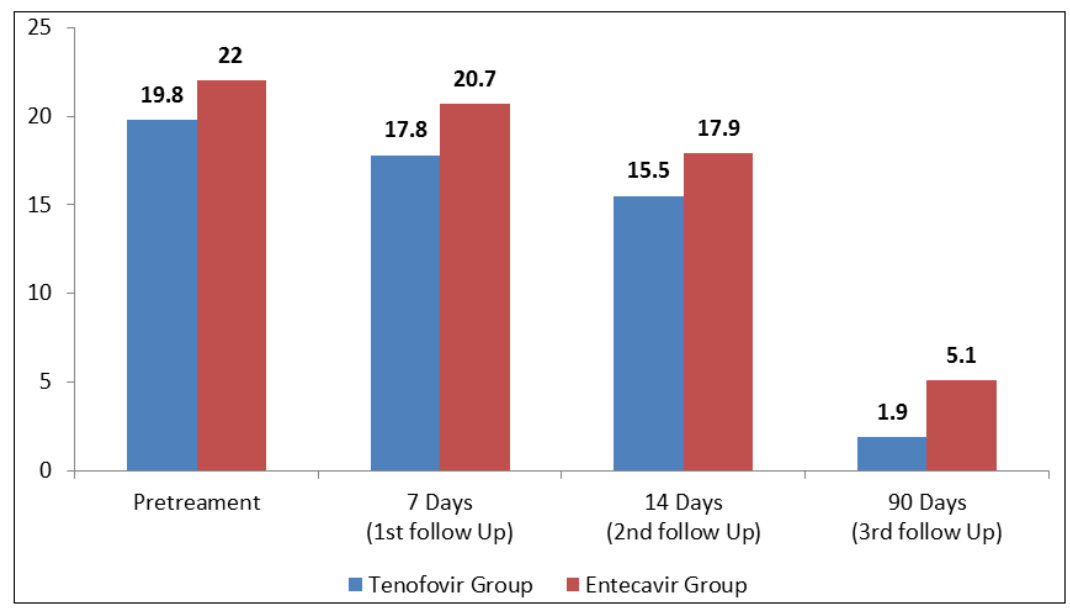

Fig-1: Different Follow up of Serum Bilirubin mean in Tenovir and Entacavir group

Different follow up of serum Bilirubin mean n=32 Patients Figure-2 shows (19.8), (22) patients mean tenofovir and Enteccavir group respectively had pretreament, (17.8), (20.7) patients mean tenofovir and Enteccavir group respectively had 7 days (First Follow- up), (15.5), (17.9) patients mean tenofovir and Enteccavir group respectively had 14 days (Second Follow-up) and (1.9), (5.1) patients mean tenofovir and Enteccavir group respectively had 90 days (Third Follow-up).

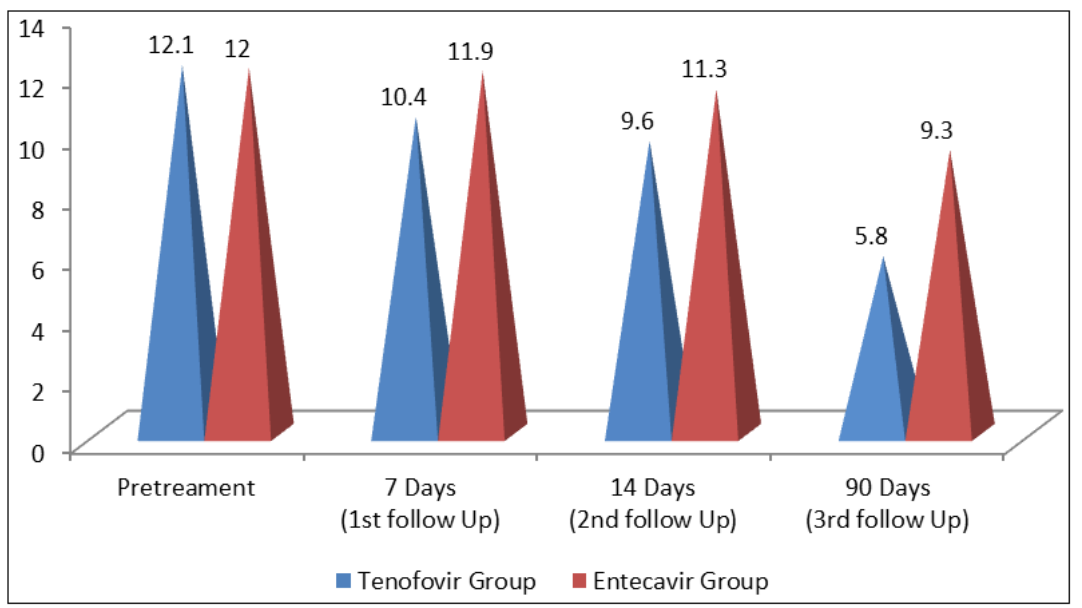

Fig-2: Different Follow up of CTP (Child-Turcotte Pugh score) mean in Tenovir and Entacavir group

Different follow up of CTP (Child-Turcotte Pugh score) mean $n=32$ patients Figure-2 shows (12.1), (12) patients mean tenofovir and Enteccavir group respectively had pretreament, (10.4), (11.9) patients mean tenofovir and Enteccavir group respectively had 7 days (First Follow-up) , (9.6), (11.3) patients mean 
tenofovir and Enteccavir group respectively had 14 days (Second Follow-up) and (5.8), (9.3) patients mean tenofovir and Enteccavir group respectively had 90 days (Third Follow-up).

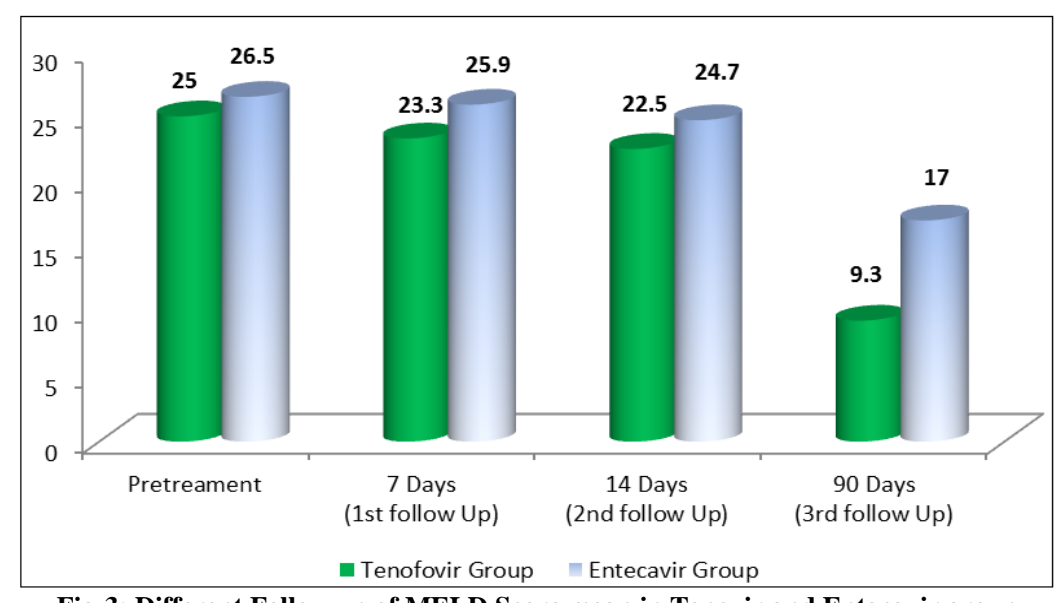

Fig-3: Different Follow up of MELD Score mean in Tenovir and Entacavir group

\section{DISCUSSION}

Different follow up of MELD Score mean n=32 Patients Figure-3 shows (25), (26.5) patients mean tenofovir and Enteccavir group respectively had pretreament, (23.3), (25.9) patients mean tenofovir and Enteccavir group respectively had 7 days (First Followup), (22.5), (24.7) patients mean tenofovir and Enteccavir group respectively had 14 days (Second Follow-up) and (9.3), (17) patients mean tenofovir and Enteccavir group respectively had 90 days (Third Follow-up). This randomized clinical trial was carried out with an aim to measure serum bilirubin, CTP score, MELD score and HBV DNA load among patients with acute on chronic hepatitis B liver failure 03 months after the antiviral (tenofovir or entecavir) therapy and to see survival of patients at 3 months among patients with acute on chronic hepatitis B liver failure 03 months after the antiviral (tenofovir or entecavir) therapy. A characteristic feature of ACLF is its rapid progression, the requirement for multiple organ supports and a high incidence of short and medium term mortality of $50 \%$ $90 \%$ [2]. Available data indicate that ICU mortality for ACLF ranges from $35 \%$ to $89 \%$ and in-hospital mortality ranges from $43 \%$ to $88 \%$, Although different criteria were employed in patient selection and followup, a careful evaluation of these data demonstrates that patient outcome is not merely determined by the severity of liver disease as expressed by conventional scoring systems (such as the Child-Pugh score), while the development and degree of end-stage organ failure represents the main determinant of outcome in ACLF patients. In one study, 3-month mortality for ACLF was predicted using MELD score. Diagnosis of ACLF is made on the basis of APASL criteria; "Acute hepatic insult manifesting as Jaundice (serum bilirubin $\geq 5$ $\mathrm{mg} / \mathrm{dl}$ ) and coagulopathy (INR $\geq 1.5$ ) complicated within 4 weeks by ascites and/or encephalopathy in a patient with previously diagnosed or undiagnosed chronic liver disease" [1]. To establish this criteria patients history, examination and laboratory assessment is needed. History of Anorexia, nausea. vomiting and duration of Jaundice.Itching. Colour of urine and faeces, Fatigue and weight loss, duration of swelling of legs or abdomen, Abdominal pain, duration of altered of level of consciousness, Haemorrhage from nose, gums, skin, alimentary tract, Loss of libido, impotence menstrual history, Past history of jaundice, hepatitis, drugs ingested, blood transfusion and alcohol consumption. Family history of liver disease, autoimmune disease. On examination: Nutrition, fever, fetor hepaticus, jaundice, pigmentation, purpura, finger clubbing, leuconychia, vascular spiders, palmar erythema, gynaecomastia (in case male),breast atrophy (in case female) distribution of body hair, parotid enlargement, Dupaytren's contracture, flapping tremor, Peripheral oedema. On Abdomen examination: visible engorged veins, liver, spleen testicular atrophy (in case male), ascites. Neurological changes: mental functions, stupor, level of consciousness. Investigations: Haematology: haemoglobin, leucocyte and platelet count, prothrombin time (INR), Serum biochemistry: Bilirubin, Alanine transaminase, Aspartate transaminase, alkaline phosphatase, serum albumin, serum sodium, potassium, bicarbonate, chloride, urea and creatinine levels, $\alpha-$ fetoprotein. Diagnosis of HBV: Serological tests for hepatitis B surface antigen (HBsAg), hepatitis B e antigen (HBeAg), immunoglobulin $\mathrm{M}$ (IgM) anti-HBc, total anti-HBc, and anti-HBe by commercially available enzyme-linked immunoassays. HBV DNA estimation with the realtime polymerase chain reaction (PCR) method. Anti $\mathrm{HCV}$ by commercially available enzyme-linked immunoassays. Acute liver injury by anti HAV IgM, anti HEV IgM. Endoscopy of upper gastrointestinal tract, and ultrasound of abdomen. Severity of the liver disease was assessed by CTP and MELD score.

Entecavir and tenofovir are currently preferred for the treatment of decompensated cirrhosis because of greater antiviral potency and a high genetic barrier to resistance [21]. In a multinational study, 191 patients 
with decompensated cirrhosis (mean CTP score 8.8, Model for End-Stage Liver Disease [MELD] score 17.1) were treated with entecavir or adefovir for up to 96 weeks [22]. Entecavir was more effective in viral suppression, and also caused improvement or stabilization in both scores. However there are few direct comparisons between entecavir and tenofovir in decompensated cirrhosis. In a randomized, controlled study by Liaw et al., [22] of 112 patients with mildly decompensated cirrhosis (average MELD score 11, CTP score 7), HBV DNA at week 48 was undetectable in $71 \%$ of tenofovir-treated patients and $73 \%$ treated with entecavir. In this present study in tenofovir patients, mean Child Pugh score was $12.1 \pm 1.3$ in pre-treatment and $7.2 \pm 1.3$ at 90 days, while mean MELD score was $25.0 \pm 3.1$ in pre-treatment and $9.3 \pm 3.2$ at 90 days. It was observed that S. Bilirubin, INR, ALT, Child-Turcotte Pugh score and MELD score had significant $(\mathrm{p}<0.05)$ decline at 90 days in tenofovir group. Serum albumin increased significantly $(\mathrm{p}<0.05)$ at 90 days in this group, which indicates that the present study showed tenofovir significantly improves serum bilirubin, serum albumin, Child-Turcotte Pugh (CTP) and model for end stage liver disease (MELD) scores 3 months after therapy. In the surviving patients Garg et al., [23] found there was a significant improvement in the, serum bilirubin, Child-Turcotte Pugh (CTP) and model for end stage liver disease (MELD) scores in the tenofovir group, whereas these parameters did not change significantly in the placebo group.

Prognostic scores for ACLF: CTP, MELD, SOFA, and APACHE scores are generally not different in patients with different etiologies of ACLF [1]. Serum creatinine (mg/dl).

Total bilirubin(mg/dl), INR(=international normalized ratio ) It is calculated according to the following formula: $\mathrm{MELD}=3.8[\mathrm{Ln}$ serum bilirubin $(\mathrm{mg} / \mathrm{dL})]+11.2[\mathrm{Ln}$ INR] $+9.6[\mathrm{Ln}$ serum creatinine $(\mathrm{mg} / \mathrm{dL})]+6.4$ (Where $\mathrm{Ln}$ is the natural logarithm) Interpretation: In interpreting the MELD Score in hospitalized patients, the 3 month mortality is: 40 or more $-71.3 \%$ mortality, 30-39-52.6\% mortality, 20-29-19.6\% mortality, 10-19-6.0\% mortality <9 - $1.9 \%$ [24]. Tenofovir significantly reduces HBVDNA levels, improves CTP and MELD scores, and reduces mortality in patients with severe spontaneous reactivation of $\mathrm{CHB}$ presenting as ACLF. Reduction in HBV-DNA levels at 2 weeks should be a desirable goal and is a good predictor of survival. Garg et al., [23] demonstrated that tenofovir therapy in ACLF patients significantly reduced the serum HBV DNA levels, improved the CTP and thereby reduced mortality, which are consistent with the current study. In another study Cui et al., [25], on the other hand, observed that entecavir did not improve liver function and MELD scores significantly in ACLF. No significant difference in 3-month survival was also observed, although levels of HBV DNA was lower. Entecavir treatment did not improve the short term prognosis of patients with HBVassociated ACLF in Cui et al., study, although it was efficacious and safe in the management of HBV DNA levels. We have also made similar observation in the present study [25].

\section{LIMITATIONS OF THE STUDY}

The study population was selected from one selected hospital in Dhaka city, so that the results of the study may not be reflect the exact picture of the country. Due to the lack of availability of the liver transplantation facility in our institute, a decision for early enrollment for the life-saving treatment option could not be offered to the patients. A larger sample size could have helped in better identifying the predictors of mortality, especially in defining them with respect to disease course and respective organ failure.

\section{CONCLUSION}

In HBV-ACLF patients, the use of nucleoside and nucleotide analogs has clear survival benefit, which is significantly higher with Tenofovir. Early intervention by antiviral therapy improves survival rates of HBV-ACLF patients and early intervention by tenofovir improves more survival. There is no cure for hepatitis B. The good news is it usually goes away by itself in 4 to 8 weeks.

Funding: No funding sources.

Conflict of interest: None declared.

Ethical approval: The study was approved by the Institutional Ethics Committee.

\section{REFERENCES}

1. Sarin SK, Kumar A, Almeida JA, Chawla YK, Fan ST, Garg H, de Silva HJ, Hamid SS, Jalan R, Komolmit P, Lau GK. Acute-on-chronic liver failure: consensus recommendations of the Asian Pacific Association for the study of the liver (APASL). Hepatology international. 2009 Mar 1;3(1):269-282.

2. Jalan R, Stadlbauer V, Sen S, Cheshire L, Chang YM, Mookerjee RP. Role of predisposition, injury, response and organ failure in the prognosis of patients with acute-on-chronic liver failure: a prospective cohort study. Critical care. 2012 Dec 1;16(6):R227.

3. Sarin SK, Kedarisetty CK, Abbas Z, Amarapurkar D, Bihari C, Chan AC, Chawla YK, Dokmeci AK, Garg H, Ghazinyan H, Hamid S. Acute-on-chronic liver failure: consensus recommendations of the Asian Pacific Association for the Study of the Liver (APASL) 2014. Hepatology international. 2014 Oct 1;8(4):453-71.

4. Vizzutti F, Arena U, Laffi G, Marra F. Acute on chronic liver failure: From pathophysiology to 
clinical management. Trends in Anaesthesia and Critical Care. 2013 Jun 1;3(3):122-9.

5. Peng CY, Chien RN, Liaw YF. Hepatitis B virusrelated decompensated liver cirrhosis: benefits of antiviral therapy. Journal of hepatology. 2012 Aug $1 ; 57(2): 442-50$.

6. Perz JF, Armstrong GL, Farrington LA, Hutin YJ, Bell BP. The contributions of hepatitis B virus and hepatitis $\mathrm{C}$ virus infections to cirrhosis and primary liver cancer worldwide. Journal of hepatology. 2006 Oct 1;45(4):529-38.

7. Tsubota A, Arase Y, Suzuki F, Sezaki H, Hosaka T. Lamivudine monotherapy for spontaneous severe acute exacerbation of chronic hepatitis B', J Hepatol, 2003; 38, 322-327.

8. Sera T, Hiasa Y, Michitaka K, Konishi I, Matsuura $\mathrm{K}$, Tokumoto $\mathrm{Y}$, Matsuura B, Kajiwara T, Masumoto T, Horiike N, Onji M. Anti-HBspositive liver failure due to hepatitis $\mathrm{B}$ virus reactivation induced by rituximab. Internal Medicine. 2006;45(11):721-4.

9. Kohrt HE, Ouyang DL, Keeffe EB. Antiviral prophylaxis for chemotherapy-induced reactivation of chronic hepatitis $B$ virus infection. Clinics in liver disease. 2007 Nov 1;11(4):965-91.

10. Sheng WH, Kao JH, Chen PJ, Huang LM, Chang SY, Sun HY, Hung CC, Chen MY, Chang SC. Evolution of hepatitis B serological markers in HIV-infected patients receiving highly active antiretroviral therapy. Clinical Infectious Diseases. 2007 Nov 1;45(9):1221-9.

11. Flink HJ, Sprengers D, Hansen BE, van Zonneveld M, De Man RA, Schalm SW, Janssen HL. Flares in chronic hepatitis B patients induced by the host or the virus? Relation to treatment response during Peg-interferon $\alpha-2 b$ therapy. Gut. 2005 Nov 1;54(11):1604-9.

12. Perceau G, Diris N, Estines O, Derancourt C, Lévy $\mathrm{S}$, Bernard P. Late lethal hepatitis $\mathrm{B}$ virus reactivation after rituximab treatment of lowgrade cutaneous B- cell lymphoma. British Journal of Dermatology. 2006 Nov;155(5):1053-6.

13. Hsieh CY, Huang HH, Lin CY, Chung LW, Liao YM. Rituximab-induced hepatitis $\mathrm{C}$ virus reactivation after spontaneous remission in diffuse large B-cell lymphoma. Journal of clinical oncology. 2008;26(15):2584-5.

14. Kumar M, Sharma BC, Sarin SK. Hepatitis E virus as an etiology of acute exacerbation of previously unrecognized asymptomatic patients with hepatitis $B$ virus- related chronic liver disease. Journal of gastroenterology and hepatology. 2008 Jun;23(6):883-7.

15. Mahtab MA, Rahman S, Khan M, Karim MF. Hepatitis $\mathrm{E}$ virus is a leading cause of acute-onchronic liver disease: experience from a tertiary centre in Bangladesh. Hepatobiliary \& pancreatic diseases international: HBPD INT. 2009 Feb;8(1):50-2.
16. Chung RT, Friedman LS. Bacterial, parasitic, and fungal infections of the liver, including liver abscess', In Feldman M, Friedman LS, Brandt LJ, editors. Sleisenger and Fordtran's Gastrointestinal and Liver Disease. 8th ed. Philadelphia, 2006; 1731.

17. Laleman W, Wilmer A, Evenepoel P, Vander Elst I, Zeegers M, Zaman Z, Verslype C, Fevery J, Nevens F. Effect of the molecular adsorbent recirculating system and Prometheus devices on systemic haemodynamics and vasoactive agents in patients with acute-on-chronic alcoholic liver failure. Critical Care. 2006 Aug 1;10(4):R108.

18. Duseja A, Chawla YK, Dhiman RK, Kumar A, Choudhary N, Taneja S. Non-hepatic insults are common acute precipitants in patients with acute on chronic liver failure (ACLF). Digestive diseases and sciences. 2010 Nov 1;55(11):318892.

19. Ripoll C, Groszmann R, Garcia-Tsao G, Grace N, Burroughs A, Planas R, Escorsell A, Garcia-Pagan JC, Makuch R, Patch D, Matloff DS. Hepatic venous pressure gradient predicts clinical decompensation in patients with compensated cirrhosis. Gastroenterology. 2007 Aug 1;133(2):481-8.

20. del Olmo JA, Flor-Lorente B, Flor-Civera B, Rodriguez F, Serra MA, Escudero A, Lledó S, Rodrigo JM. Risk factors for nonhepatic surgery in patients with cirrhosis. World journal of surgery. 2003 Jun 1;27(6):647-52.

21. Perrillo RP. Hepatitis B virus treatment: Which patients require immediate treatment. Clinical liver disease. 2013 Feb;2(1):11-14.

22. Liaw YF, Raptopoulou- Gigi M, Cheinquer H, Sarin SK, Tanwandee T, Leung N, Peng CY, Myers RP, Brown Jr RS, Jeffers L, Tsai N. Efficacy and safety of entecavir versus adefovir in chronic hepatitis B patients with hepatic decompensation: a randomized, open- label study. Hepatology. 2011 Jul;54(1):91-100.

23. Garg H, Sarin SK, Kumar M, Garg V, Sharma BC, Kumar A. Tenofovir improves the outcome in patients with spontaneous reactivation of hepatitis B presenting as acute- on- chronic liver failure. Hepatology. 2011 Mar;53(3):774-80.

24. Kamath PS, Wiesner RH, Malinchoc M, Kremers W, Therneau TM, Kosberg CL, D'Amico G, Dickson ER, Kim WR. A model to predict survival in patients with end-stage liver disease. Hepatology. 2001 Feb;33(2):464-70.

25. Cui YL, Yan F, Wang YB, Song XQ, Liu L, Lei XZ, Zheng MH, Tang H, Feng P. Nucleoside analogue can improve the long-term prognosis of patients with hepatitis B virus infection-associated acute on chronic liver failure. Digestive diseases and sciences. 2010 Aug 1;55(8):2373-80. 